\section{Innovation in oncology drug development}

A focus on patient benefits

\begin{tabular}{|c|c|c|}
\hline $\begin{array}{l}\text { Innovation in oncology drug } \\
\text { development is driving } \\
\text { more efficient and effective } \\
\text { development of new cancer } \\
\text { treatments. This innovation } \\
\text { is providing cancer patients } \\
\text { unprecedented access to new } \\
\text { therapies. Dr Brian Huber, } \\
\text { Vice President of Therapeutic } \\
\text { Areas, Drug Development } \\
\text { and Consulting at ICON and } \\
\text { Matthew Huber, a scientist in } \\
\text { the emerging biotechnology } \\
\text { sector focused on developing } \\
\text { innovative oncology medicines, } \\
\text { have conducted a review that } \\
\text { highlights how innovation, from } \\
\text { the development of targeted } \\
\text { therapies to a revolution in } \\
\text { clinical trial designs, puts an } \\
\text { emphasis on patient centricity. }\end{array}$ & $\begin{array}{l}\text { rogress in the treatment of cancer } \\
\text { continues. Better prevention, } \\
\text { earlier detection, more extensive } \\
\text { knowledge of the causative genetic } \\
\text { lesions and development of new } \\
\text { therapies lead, year after year, to a } \\
\text { decrease in cancer mortality. However, } \\
\text { despite more and more frequent success } \\
\text { stories, some cancers remain resistant to } \\
\text { all therapies. There is a critical medical } \\
\text { necessity to be able to bring better } \\
\text { medicines to these patients more quickly } \\
\text { and more effectively regarding time, } \\
\text { cost, and probability of success. } \\
\text { Innovation in oncology clinical drug } \\
\text { development is needed, not only to } \\
\text { enable more effective and efficient } \\
\text { development of new cancer therapies, } \\
\text { but also to give patients - including } \\
\text { those with rare forms of cancer - access } \\
\text { to new therapies much sooner. Many } \\
\text { initiatives currently undertaken aim to }\end{array}$ & $\begin{array}{l}\text { make the oncology drug development } \\
\text { process more patient-centric. Dr Brian } \\
\text { Huber from ICON PLC and Matthew } \\
\text { Huber, MS, conducted a recent review } \\
\text { of the oncology drug development } \\
\text { process, highlighting this pivot to a } \\
\text { more patient-centric approach and the } \\
\text { benefits this can bring. } \\
\text { TARGETED THERAPIES } \\
\text { Until thirty years ago, knowledge } \\
\text { of tumours mostly consisted of } \\
\text { observations about the behaviour of } \\
\text { tumour cells: it was known that tumour } \\
\text { cellls divide faster than most normal } \\
\text { cells, that they are able to migrate and } \\
\text { invade normal tissues, that they can } \\
\text { evade recognition and destruction } \\
\text { by the immune system, and that they } \\
\text { seem to evade normal mechanisms of } \\
\text { cell death - senescence and apoptosis. } \\
\text { Therapies developed back then were } \\
\text { 'cytotoxic' drugs whose cell-destroying } \\
\text { actions were largely based upon the } \\
\text { observation that cancer cells divide } \\
\text { more rapidly than most normal cells } \\
\text { in the body. This property provided a } \\
\text { minimal amount of selectivity of the } \\
\text { cytotoxic agent for the cancer cell over } \\
\text { the normal cells. Of course, normal } \\
\text { cells that divide rapidlly, such as cells in } \\
\text { the bone marrow and gastrointestinal } \\
\text { tract, have very little protection from } \\
\text { the yctotoxic agent, causing serious } \\
\text { side effects. Starting in the late } 1980 \text { s, } \\
\text { however, there was an explosion in the } \\
\text { understanding of the molecular lesions } \\
\text { that cause and maintain the tumour's } \\
\text { unique characteristics. This molecular } \\
\text { understanding has resulted in the }\end{array}$ \\
\hline
\end{tabular}

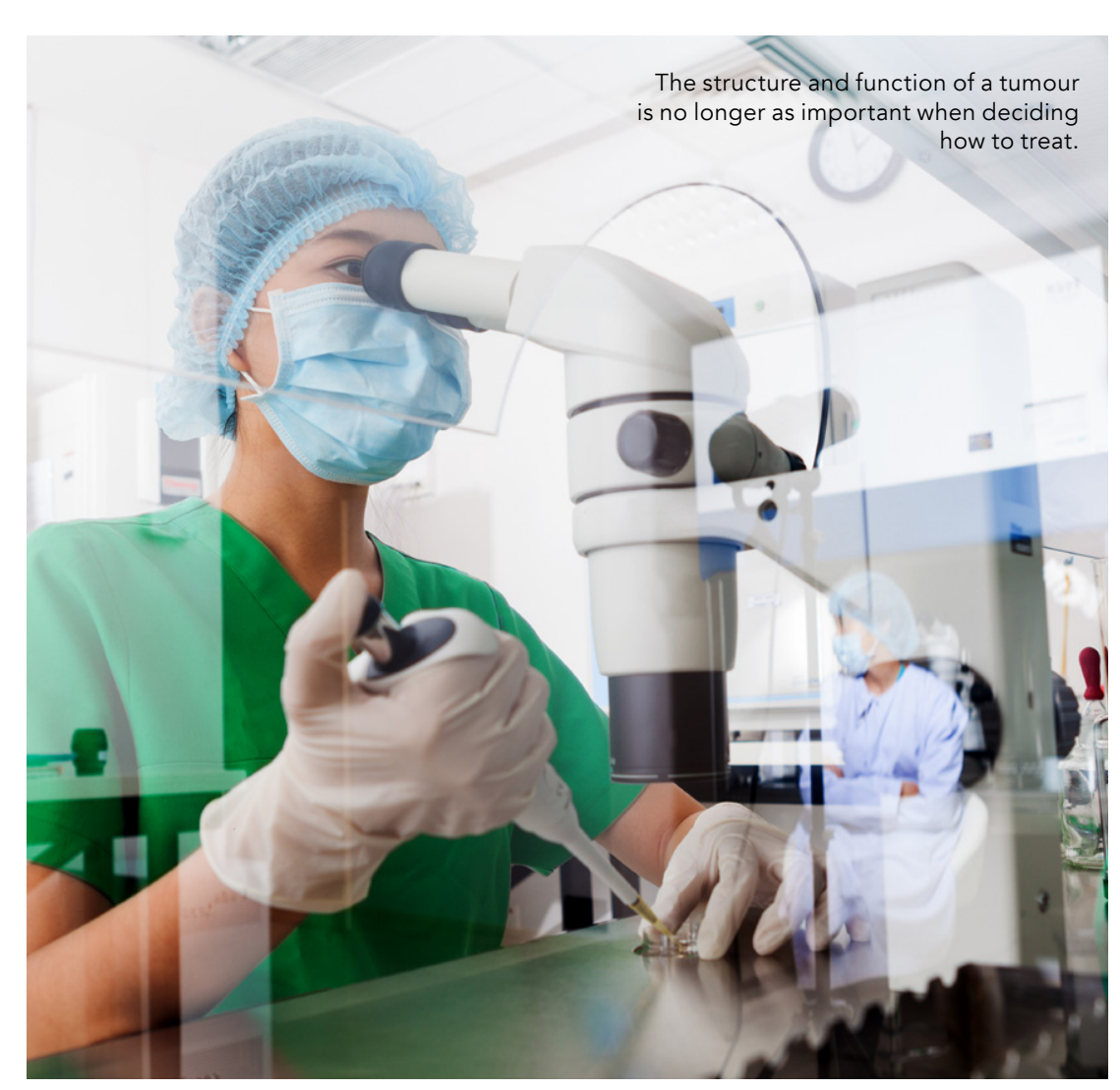

Cancer treatment is now based on the presence of specific genetic lesions rather than the tissue of origin or site of tumour.

development of targeted therapies that are each specific to a certain type of genetic lesion.

PRECISION MEDICINE

With the development of targeted therapies came the era of precision model involves identifying the molectar lesions that are present in a tumour and then selecting the treatments th specifically target these lesions. Besides precisely targeting specific lesions, this approach also means clinicians can avoid using these targeted drugs in patients whose tumours do not harbour the relevant lesion, as these patients would experience little to no clinical benefit from these drugs.

Precision medicine is not a new medical concept, but the ability to examine the genotype (genetic information) and phenotype (set of expressed characteristics) of tumour cells to identify greatly advanced over the last twenty subpopulation \#1 will be treated $w$ i with specific targeted therapies has years. Precision medicine aims to us the most appropriate treatment for right patient, at the right time, and at the right dose. This is especially important similar tumour structure the tumour 'histology' may actually contain patient subpopulation since their tumours have different genetic as an example. Melanom patients in subpopulation \#1 contain tumours with lesion $\mathrm{A}$; patients in subpopulation \#2 contain tumours with lesion B. Patients in a specific targeted herapy for lesion Awille pations in subpopulation 12 therapy for lesion B. This becomes

especially relevant when a specific penetic lesion occurs only in a low precision medicine, cancer treatment is now based on the presence of specific genetic lesions rather than the tissue of origin or site of tumour. This approach has been proven to be much more effective than the traditional histologybased approach, where all patients with melanomas would receive the

SITE-AGNOSTIC APPROVA As therapies evolved, innovation in dru development and approval processes was needed. With the traditional histology-based approach, each therapy was approved for a certain type of cancer based upon the histology and line of therapy. With the development of clear that various genetic lesions con cause a specific type of cancer and most importantly, different cancers be caused by similar genetic lesions.

Traditionally, a drug that was approved for a certain type of cancer needed to go through another trial and application to be approved for another type of cancer harbouring the exact same molecular lesion. Now, however, the FDA (U.S. Food and Drug Administration) has innovated and adapted the process: in 2017 , the first site-agnostic approval was granted for pembrolizumab, whic wecame the first ding approved for all genetic lesion called instability-high,

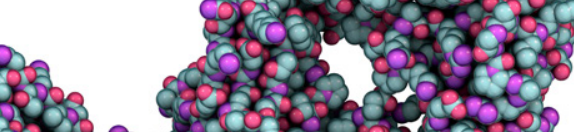




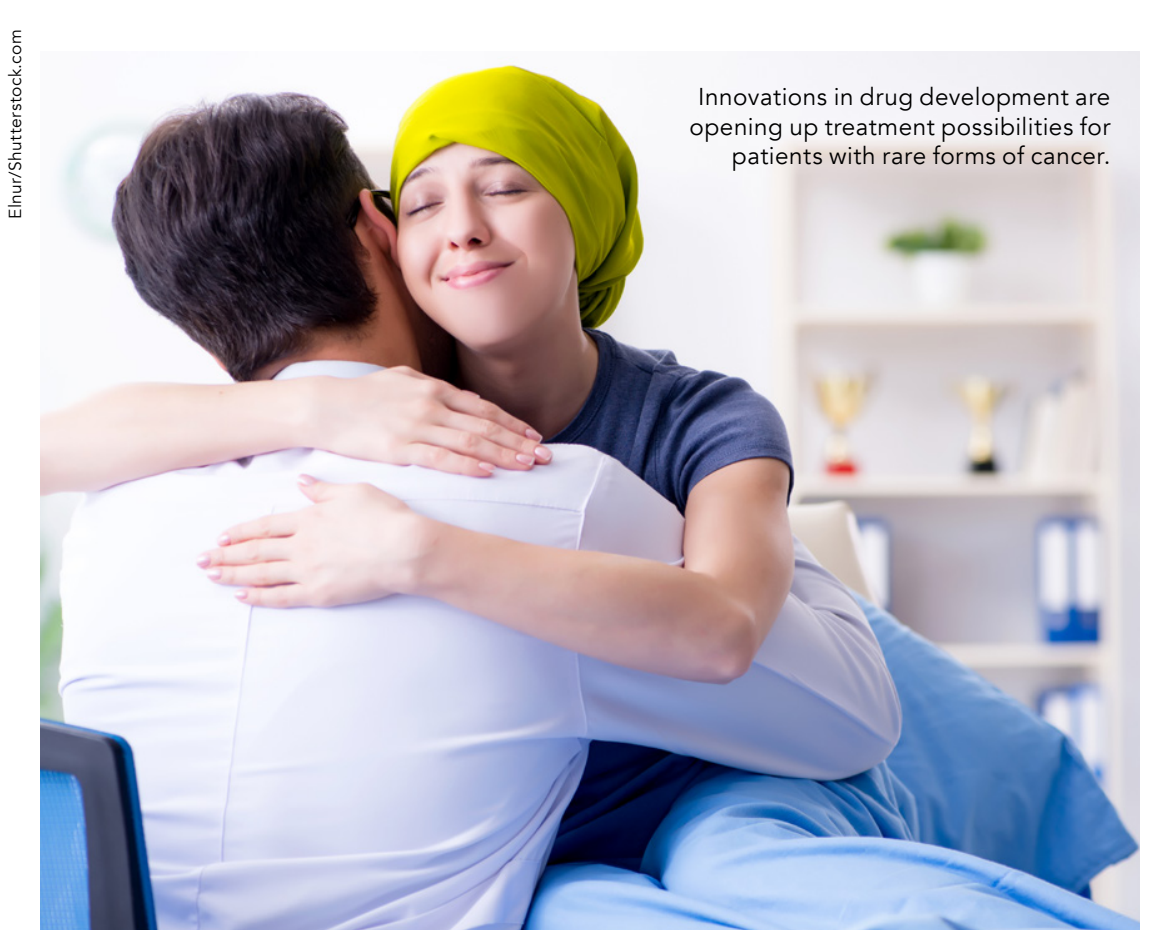

Clinical trials have now become an important care option for patients.

regardless of the tissue of origin or the site of the tumour.

With site-agnostic approval, patients will not need to wait indefinitely for a specific study to be conducted in their tumour histology followed by FDA approval for reimbursement. This will make new therapies available more quickly to a broader range of cancers. Patients with rare forms of cancer but with similar genetic lesions developed therapies.

\section{ADAPTIVE TRIAL DESIGN}

Traditionally, clinical trials were designed to rigidly follow a prospective protocol during which patients receive a predetermined therapy for a fixed period of time. More and more, clinical trials are evolving towards a more adaptive design that gives (t) While the trial progresses. Researchers can see how patients are responding cordingly to madapt the protocol and effective. An adpive tificient also allows new scientic und destign and discovery to be taken into account Adaptive trial designs are as scientifecly
In basket trials, patients are selected their tumours. On arete lesions of is tested on patients that harbour on secific genetic signature, regardless of the type of cancer histology: patients with melanomas and patients with ovarian cancers, for example, can take part in the same basket trial if their tumours harbour the targeted genetic signature. This is more efficient than evaluating different types of cancer separately, especially if the genetic signature is relatively rare in a particular type.

Basket trials are especially beneficial to patients expressing a genetic signature that is rare for their type of cancer. In the traditional way, specific studies in these rave forms of cancer In basket trials, however, these patients can be included along with patients with other types of cancers that share the same genetic signature. Basket trials therefore grant them greater access to innovative targeted therapies.

robust as traditional trials, but they allow some flexibility for clinical investigators trial progresses.

While traditional clinical trials were divided into phases that constituted very distinct and separate stages, phases are now evolving into a seamless continuu cost, time and

Traditionally, only patients with little to parting took with a focus on precision medicine that tries to select the right drug for the

right patient clinical trials have becom an essential part of comprehensive treatment options for cancer patients.

BASKET AND UMBRELLA TRIALS With the development of targeted therapies, further innovation in trial design led to two new strategies: the basket and umbrella trial. Traditiona clinical trials that test nonspecific cytotoxic drugs were usually studied in cancer patients who have little to no alternative treatment options, regardless of tumour histology, in basket and more carefully.
In umbrella trials, all patients have the same type of cancer. Since a specific type of cancer can be defined by different genetic signatures, an umbrella trial evaluates multiple targeted therapies, with each patient being tributed the therapy that is relevant to

\section{FDA ADAPTABILITY}

\section{IND INNOVATION}

Innovation in oncology drug

FA. Besides granting steng at the

approvals, the FDA has developed

programs ssuch as Accelerated

Approval, Fast Track, Breakthrough

Therapy, Priority Review) that aim to

"address significant unmet medical

need in the treatment of a serious or

life-threatening condition" by reviewing

drugs faster and providing an expedited review process. Thus providing cancer patients early access to new therapies.

s the review from Dr Brian Huber and Matthew Huber, MS, highlights, the move to a more patient-centic approach has many benefis for patients, care providers and drug

\section{Behind the Research}

Dr Brian

Huber

E: Brian.Huber@iconplc.com T: +1 (919) 294-2238
M: +1 (919) 724-5555

W: www.iconplc.com/oncology

/icon-plc-2/_0@iconplc

\section{Research Objectives}

Dr Brian Huber and Matthew Huber have conducted a review of innovation in oncology drug development, highlighting the need for a patient-centric approach.

$\begin{array}{lll}\text { Detail } & & \\ \text { Brian Huber } & \text { Bio } & \text { Wellcome and Senior staff fellow at } \\ \text { ICON plc } & \text { Brian Huber, PhD is a leader } & \text { the National Cancer Institute, NIH, in } \\ \text { 79 T.W. Alexander Drive } & \text { in the Biopharmaceutical Drug } & \text { Bethesda, MD. Dr Huber has 11 issued } \\ \text { 4401 Research Commons Bldg } & \text { Development, CRO Service and } & \text { patents, 65 publications in peer- } \\ \text { Suite 300 } & \text { Investment Sectors, with over 35 } & \text { reviewed journals and a number of } \\ \text { Durham, NC 27709 } & \text { years' experience. His current position } & \text { books and book chapters. } \\ \text { USA } & \text { is the Vice President of Therapeutic } & \\ & \text { Areas, Drug Development and } & \text { Matthew Huber, MS is a scientist in } \\ \text { Matthew Huber } & \text { Consulting at ICON. Dr Huber's } & \text { the emerging biotechnology sector } \\ \text { Department of Medicine } & \text { experiences include VP \& Managing } & \text { focused on developing innovative } \\ \text { Georgetown University Medical Center } & \text { Director at Quintiles / IOVIA; Global } & \text { oncology medicines. He received his } \\ \text { 400 Reservoir Road NW } & \text { VP in Drug Discovery at GSK, CEO of } & \text { BS degree from University of North } \\ \text { Washington, DC 20007 } & \text { Shionogi / GW Pharmaceutical Inc.; } & \text { Carolina at Chapel Hill and his MS } \\ \text { USA } & \text { Director of Oncology at Burroughs } & \text { degree from Georgetown University. }\end{array}$

\section{References}

Huber M., \& Huber B. (2019). Innovation in Oncology Drug Development. Journal of Oncology, 2019, 9683016. https://doi.org/10.1155/2019/9683016

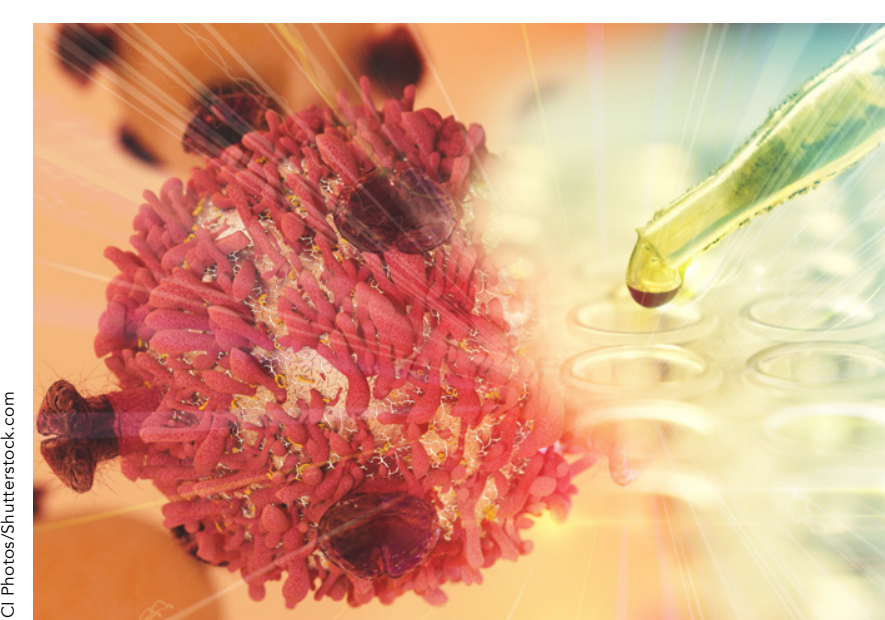

\section{Personal Response}

What would you say is the next innovative step in Whology drug development?

II Currently cancer is treated when there are clinical manifestations of the tumour burden, such as a palatable lump, pain, bleeding, weight loss or other signs and symptoms there is already the presence of significant tumour burden

Greater attention will be focused on tumour detection at a sub-clinical stage using sensitive biomarkers,
circulating tumour cells or circulating tumour DNA. This circulating tumour cells or circulating tumour DNA. This
will allow treatment to begin at a stage with significantly
less tumour burden to treat. 